\title{
THE ROLE OF RESIDENCE NEAR HAZARDOUS WASTE SITES CONTAINING BENZENE IN THE DEVELOPMENT OF HEMATOLOGIC CANCERS IN UPSTATE NEW YORK
}

\author{
ERIK BOBERG ${ }^{1,2}$, LAWRENCE LESSNER ${ }^{2}$, and DAVID 0. CARPENTER ${ }^{2}$ \\ ${ }^{1}$ Linköping University, Linköping, Sweden \\ ${ }^{2}$ University at Albany, Rensselaer, New York, USA \\ Institute for Health and the Environment
}

\begin{abstract}
Objectives: Epidemiologic studies suggest an association between environmental exposure to benzene and hematologic cancers, but the relationship is not firmly established. The aim of this study was to assess the potential association between residence near hazardous waste sites containing benzene and hospitalization discharge rates for persons having hematologic cancers. Materials and Methods: We determined the number of hospital discharges of people with hematologic cancers in New York State except for New York City for the years 1993 to 2008. Descriptive statistics and negative binomial regression models were used to compare the rates of hospitalization of residents in zip codes containing hazardous waste sites containing benzene to the rates of discharges from residents in zip codes without waste sites. Results: When adjusting for potential confounders we found a $15 \%$ increase in the rate of hospitalization for chronic lymphatic leukemia (CLL) [rate ratio (RR): 1.15; 95\% confidence interval (CI): 1.00-1.33], a 22\% increase in the rate of discharges for total leukemia (RR: 1.22; $95 \%$ CI: 1.04-1.43) and a 17\% increase in the rate of discharges for total lymphoma (RR: 1.17; 95\% CI: 1.02-1.35) in the benzene exposed sites. We found greater effects of exposure in African Americans compared to Caucasians, females compared to males and people with higher socioeconomic status (SES) compared to those with lower SES for several of the diseases studied. Conclusions: After controlling for major confounders we found statistically significant increases in discharge rates for several hematologic cancers in persons residing in zip codes containing benzene waste sites. These results provide additional support for a relationship between environmental exposure to benzene and risk of hematologic cancers.
\end{abstract}

Key words:

Environmental exposure, Lymphoma, Leukemia, Ecological study, Ethnic difference

\section{INTRODUCTION}

Hematologic cancers constitute a diverse group of diseases of largely unknown etiology. Even though they are considered to be a rare group of cancers, more than a 100000 new cases of hematologic cancers were diagnosed in the United States in 2005. In the same year more than 53000 people died from these diseases [1].
There are few established risk factors for hematologic cancers, but some associations have been confirmed. Cigarette smoking and exposure to ionizing radiation have been shown to cause leukemia in some studies [1-3]. Further, leukemia is more common in Caucasians than in AfricanAmericans and more common in males than females $[1,4]$. Immunosuppression, both in transplant recipients and in

Received: November 1, 2010. Accepted: August 4, 2011.

Address reprint request to D.O. Carpenter, Institute for Health and the Environment, University at Albany, 5 University Place, A217, Rensselaer, NY 12144, USA (e-mail: carpent@uamail.albany.edu). 
people with AIDS has been shown to increase the risk of non-Hodgkin's lymphoma (NHL) [5]. NHL is also more common in Caucasians than in African-Americans and more common in males than in females [4]. Based on epidemiologic findings, Hodgkin's Disease (HD) can be divided into three different diseases: childhood (0-14), young adult (15-34) and older adult (> 55) HD [6]. A relationship between Epstein-Barr virus (EBV) infection and the risk of HD has been established, but the underlying mechanisms are unknown. Poliomyelitis and tuberculosis infections have been linked to young adult HD [6]. Older adult HD is more common in males than in females, but there is no difference in the younger age groups [4]. Except for HD and acute lymphatic leukemia (ALL), the incidence of all hematopoietic cancers increases with age [4].

Based on sufficient evidence of carcinogenicity in humans, benzene is rated as a known human carcinogen [7]. There is a well established relationship between occupational exposure to benzene and increased risk of hematological cancers, especially acute myelogenous leukemia [8-9]. A relationship for multiple myeloma and NHL has also been suggested by several studies [8,10-11]. A positive exposure-response relationship has also been established between benzene exposure and the odds ratio of developing leukemia [9].

Because of its wide use, benzene is among the top 20 most produced chemicals in the US. It is used in the production of other chemicals (for example styrene, cumene and cyclohexane) and in the development of some rubbers, dyes, detergents and pesticides [12]. In 2007, almost 4 million kilograms of benzene were released from industrial sources into the environment in the US. Most of that benzene was released into the atmosphere [13]. Benzene can also reach the soil and ground water near industrial waste sites and industries that use or make the chemical [13]. It is highly mobile in soil and readily leaches from soil into ground water [12]. Benzene is a highly volatile compound and consequently tends to vaporize from contaminated water into the atmosphere [14]. Large amounts of benzene are also released into the atmosphere from automobile exhaust, which accounts for up to $85 \%$ of the total atmospheric amount [15]. Benzene in air is degraded within a few days due to reaction with hydroxyl radicals [12].

Despite the large amounts in the atmosphere, the most important source of human exposure to benzene is cigarette smoke. Cigarette smoking is responsible for about half of the total benzene exposure, compared to the contribution from the industry which is $3 \%$ [12]. Cigarette smoking does not only expose the smoker to benzene, the level of benzene in the indoor air is 50\% higher in a home where at least one smoker lives, compared to a home without smokers [16]. For non-smokers, outdoor air remains the most important contribution to benzene exposure [15]. Due to the large emissions from industry and transportation, and due to the exposure from cigarette smoking, benzene is ubiquitous in the atmosphere and can be measured in the blood of non-occupationally exposed people [17]. Benzene can readily enter the body via oral, dermal and inhalation routes. Because it has slight water solubility, high lipid solubility and is non-polar, benzene is expected to enter the blood stream through passive diffusion from the gut, skin and lungs. Benzene is also expected to bind to plasma proteins [12].

Benzene is quickly metabolized by the enzyme, cytochrome P450 2E1 (CYP2E1) in the liver and the metabolites appear to be responsible for its toxicity [12]. The reactive metabolites of benzene may act directly on DNA and other macromolecules in bone marrow cells, and thus promote cellular damage and DNA mutations [12]. A study on occupationally exposed workers with a phenotype corresponding to rapid CYP2E1 metabolism showed that they are more susceptible to benzene poisoning than wild type controls [18]. The enzyme NADPH quinone oxidoreductase (NQ01) is thought to play an important role in the removal of the active metabolites of benzene. Several 
studies have shown that a polymorphism that reduces the activity of NQ01 also increases the risk of benzene poisoning [18-20].

This study examines the possible role of environmental exposure to benzene coming from hazardous waste sites on the rates of hospitalization for hematologic cancers. Our hypothesis is that the presence of environmental concentrations of benzene promotes leukemia and lymphoma in the population. The specific aim is to assess the potential association between residence near hazardous waste sites containing benzene and hospitalization rates for persons with different types of lymphatic and hematopoietic cancers among residents of New York.

\section{MATERIALS AND METHODS}

We conducted an ecological study, where the unit of study was a subpopulation of a zip code, defined by race, gender and age. For each subpopulation we included the median household income for the zip code and the percentage of the zip code population that lives in an urbanized area.

\section{Study population}

We used the New York Statewide Planning and Research Cooperative System (SPARCS) to obtain data on lymphatic and hematopoietic diseases between the years 1993 and 2008. Every hospital regulated by and located in New York State is required to report all diagnoses (up to a total of 15 diagnoses) for each inpatient, upon discharge, to the NYS department of health. To classify the diagnoses the International Classification of Disease, 9th revision (ICD-9) was used [21]. We identified all of the hospitalizations that included any of the ICD-9 codes for hematologic cancers (ICD-9 codes 200, 201, 202, 203, 204, 205, 206, 207, 208 and 238.6). We further divided these into more specific diseases including: leukemia (204, 205, 206, 207, 208 and 202.4), lymphoma (200, 201 and 202 except for 202.4) and multiple myeloma (MM, 203 and 238.6). Leukemias were further subdivided into ALL (204.0 and 204.2), CLL (204.1), acute myeloid leukemia (AML, 205.0 and 205.2) and chronic myeloid leukemia (CML, 205.1). The lymphomas were subdivided into HD (201) and NHL (200 and 202).

The SPARCS data that we used provides the diagnoses upon discharge of all in-patients from 212 hospitals in New York other than New York City. In addition to the diagnoses, the accessible data include the patient's race, gender, age and current zip code of residence. It does not identify individuals with multiple hospitalizations or patients in federally regulated hospitals (nine Veteran's Administration hospitals in New York other than New York City), nor does it include out-of-state health care treatment received by New York residents. However, these exclusions represent a very small number in relation to the total of approximately two and a half million hospitalizations per year. The dataset lists only current, not previous, residences. We examined only two racial groups (Caucasian and African American) to reduce variability. To adjust for age differences we split the population into six age groups (ages 1-14, 15-19, 20-39, 40-59, 60-79, and 80 years and older, respectively). Since ALL almost exclusively occurs in young people, we restricted the analysis of that disease to the first two age groups. All the other diseases except for HD were examined in the four oldest age groups. HD was examined in only the three oldest age groups. HD has a bimodal incidence pattern with peak incidences in early adulthood and in older people (Glaser and Jarret 1996; NCI 2009). We restricted the analysis to the peak in incidence in older people so that only one of the three diseases that constitute HD (Grufferman and Delzell 1984) would be studied. In addition, there is evidence for an infectious etiology of HD in younger age groups [22].

There are other important covariates believed to be confounders for assessing health care that are not included in the SPARCS dataset. We obtained the median 
household income (MHI) by zip code and year in all zip codes in all New York except for New York City from Claritas, Inc. MHI was used to adjust for socioeconomic status (SES). The study was restricted to the two middle quartiles (second and third quartile) of MHI because previous studies have shown that extremes of SES, as measured by MHI, have different health service access behaviors [23-24]. We further divided the remaining population into three equal percentile groups (group 1: 25th-41st percentile; group 2: 42nd-58th percentile; group 3: 59th-74th percentile). There are several reasons to control for the urbanicity of a population. People living in more urbanized areas are expected to be exposed to higher levels of motor vehicle exhaust and higher motor vehicle density. Motor vehicle exhaust is an important source of environmental benzene [15], and greater motor vehicle density has been shown to correlate with some types of leukemia [25]. People that live in urbanized areas may also access medicine in different patterns compared to those that live in rural areas. The US Census Bureau lists the number of people in each zip code that live in an urbanized area, defined as an area with a population density greater than 1000 people per square mile [26]. We used Census data from 2000 to divide the population into four groups. Group one contains the zip codes where none of the population lives in an urbanized area (635 zip codes), group two contains the zip codes where more than 0 , up to $49 \%$ of the population lives in an urbanized area (144 zip codes), group three contains the zip codes where more than $49 \%$ and less than $100 \%$ of the population lives in an urbanized area (327 zip codes) and group four contains the zip codes where the entire population is living in an urbanized area (269 zip codes).

We obtained the number of people living in each zip code by race, gender and age for each year between 1993 and 2008 from Claritas, Inc (San Diego, CA). Since the United States Postal Service regularly changes zip codes, we collected the total population and the number of discharges within each subpopulation for each year separately and added them together to create the person time variable, which then allowed determination of the hospitalization rates in the final data set. Table 1 provides a summary of the characteristics of the studied population.

Table 1. Characteristics for the study population

\begin{tabular}{|c|c|c|}
\hline Characteristic & $\begin{array}{c}\text { Total discharges } \\
(\%)\end{array}$ & $\begin{array}{c}\text { Total person-years } \\
(\%)\end{array}$ \\
\hline \multicolumn{3}{|l|}{ Exposure } \\
\hline benzene & 7977 (17.5) & 4740530 (15.9) \\
\hline unexposed & $37553(82.5)$ & $25145104(84.1)$ \\
\hline \multicolumn{3}{|l|}{ Age [years] } \\
\hline $1-14$ & $2902(6.4)$ & $5968670(20.0)$ \\
\hline $15-19$ & $963(2.1)$ & $2160295(7.2)$ \\
\hline 20-39 & $3404(7.5)$ & $8156125(27.3)$ \\
\hline $40-59$ & $9531(20.9)$ & $7982094(26.7)$ \\
\hline $60-79$ & $20146(44.2)$ & $4446498(14.9)$ \\
\hline $80+$ & 8584 (18.9) & $1171952(3.9)$ \\
\hline \multicolumn{3}{|l|}{ Gender } \\
\hline male & $24886(54.7)$ & $14749887(49.4)$ \\
\hline female & 20644 (45.3) & $15135747(50.6)$ \\
\hline \multicolumn{3}{|l|}{ Race } \\
\hline African American & $1667(3.7)$ & $1547611(5.2)$ \\
\hline Caucasian & 43863 (96.3) & 28338023 (94.8) \\
\hline \multicolumn{3}{|l|}{ Income group } \\
\hline 1 & $12299(27.0)$ & 8391279 (28.1) \\
\hline 2 & $14427(31.7)$ & 9401635 (31.5) \\
\hline 3 & $18804(41.3)$ & $12092720(40.5)$ \\
\hline \multicolumn{3}{|l|}{ Urban Group } \\
\hline 1 & $13601(29.9)$ & 9455635 (31.6) \\
\hline 2 & $5146(11.3)$ & $3429366(11.5)$ \\
\hline 3 & $16976(37.3)$ & $11049083(37.0)$ \\
\hline 4 & 9807 (21.5) & $5951550(19.9)$ \\
\hline Total & $45530(100.0)$ & $29885634(100.0)$ \\
\hline
\end{tabular}

${ }^{a}$ Sum of the population by ZIP code, 1993-2008. 


\section{Exposure assessment}

The New York State Department of Environmental Conservation has identified 818 hazardous waste sites (Superfund sites) in the state that pose a potential threat to human health (http://www.dec.state.ny.us/ website/regs/part371a.html). The list includes $85 \mathrm{Na}$ tional Priority List sites defined by the US Environmental Protection Agency [27]. Using this database we located all waste sites in New York (except New York City) that contained benzene. We defined the exposed population as all residents of the zip codes containing any of the benzene sites (40 zip codes). All zip codes that did not contain any hazardous waste sites were defined as unexposed. We also removed all zip codes that abut Onondaga Lake and the Hudson River (from the river mouth to Hudson Falls) from the clean zip codes due to the high polychlorinated biphenyl contamination in these waters [28].

\section{Statistical analysis}

We calculated hospital discharge rates per 100000 as the number of discharge diagnoses of the specific hematologic cancers divided by the total population with the same gender, race and age group, residing in the same ZIP code category defined by exposure, MHI and percentage of the population living in urbanized areas. All statistical analyses were performed with SAS software (version 9.2; SAS Institute Inc., Cary, NC). We modeled the rates of lymphatic and hematopoietic hospital discharge as Poisson processes. However, when Poisson regression, a log-linear model, was applied using PROC GENMOD (SAS Institute), the deviance test for the quality of fit of models and the residual plots indicated extra Poisson variation [29]. Consequently, we used the negative binomial regression model [30]. This model is a log-linear model (i.e., the log of the mean number of discharges is determined by the linear combination of covariates).
For all leukemia, all lymphoma, CLL, AML, CML and NHL we included all discharges for persons at least 20 years old, and used the following model:

$\log ($ expected number of discharges for the disease $)=$ $\log ($ total person-time $)+$ intercept + b1 $*$ benzene-exposure $+\mathrm{b} 2 *$ female + $\mathrm{b} 3 *$ African-American $+\mathrm{b} 4 *$ age $6+$ b5*age $5+$ b6*age $4+\mathrm{b} 7 *$ income $3+$ b8*income $2+$ b9*urban $4+$ b10*urban 3 + b11*urban $2+$ interactions

For ALL, we included only people 1-19 years of age, and employed the following model:

$$
\begin{gathered}
\log (\text { expected number of ALL discharges })= \\
\log (\text { total person-time })+\text { intercept }+ \\
\text { b1*benzene-exposure }+ \text { b2*female }+ \\
\text { b3*African American }+ \text { b4*age } 2+ \\
\text { b5*income } 3+\mathrm{b} 6 * \text { income } 2+ \\
\text { b7*urban } 4+\text { b } 8 * \text { urban } 3+\text { b } 9 * \text { urban } 2 \\
+ \text { interactions }
\end{gathered}
$$

For HD, we included only people 40 years and older and used the following model:

$$
\begin{gathered}
\text { Log (expected number of discharges for the disease })= \\
\log (\text { total person-time })+\text { intercept }+ \\
\text { b1*benzene-exposure }+\mathrm{b} 2 * \text { female }+ \\
\text { b3*African-American }+ \text { b4*age } 6+ \\
\text { b5*age } 5+\mathrm{b} 6 * \text { income } 3+\mathrm{b} 7 * \text { income } 2+ \\
\text { b8*urban } 4+\text { b } 9 * \text { urban } 3+\text { b10*urban } 2 \\
+ \text { interactions }
\end{gathered}
$$

where

age 1 is ages $1-14$,

age 2 is ages $15-19$,

age 3 is ages $20-39$,

age 4 is ages $40-59$,

age 5 is ages $60-79$,

age 6 is ages 80 and older,

income1 is the 25th to the 41st percentile of MHI,

income 2 is the 42 nd to 58 th percentile of MHI, income 3 is the 59th to 75 th percentile of MHI,

urban1 is living in a zip code where none of the population lives in urbanized areas, 
urban2 is living in a zip code where more than 0 , up to $49 \%$ of the population lives in urbanized areas,

urban3 is living in a zip code where more than $49 \%$ and less than $100 \%$ of the population lives in urbanized areas, urban4 is living in a zip code where the entire population lives in urbanized areas.

The modeling process began with the creation of a main effects only model to adjust for potential confounding. Following that, for each population, the main effects models were examined for effect modifiers in the exposure vs. outcome association. In particular, all interactions of exposure with age, gender, race, MHI and urban level were considered. We thus obtained the final models displayed above.

A residual analysis was conducted for each final model, and extreme values were identified in many of the analyses. We removed the observation with the largest standardized Pearson residual from the analysis of CLL, CML, HD, NHL and MM and removed the two observations with the highest standardized Pearson residuals from the analysis of AML. With that we improved the quality of fit of the models without changing the relationship between the exposure and the outcomes significantly.

\section{RESULTS}

Crude analysis showed statistically significant increases in discharges for all of the diseases examined except for AML and MM when comparing benzene-exposed to unexposed populations. When we applied the main effects models, CLL, total adult leukemia and total lymphoma had significantly elevated rates of discharges in the benzene-exposed populations compared to the unexposed (Table 2). We also looked at the crude rates of discharges for some of the diseases within the two racial and three income groups. The crude rate of discharges for CLL, NHL, all adult leukemia and all lymphoma were significantly larger among Caucasians as compared to African-Americans. This is consistent with data from the National Cancer Institute [4]. For HD there was no significant difference by race (Figure 1). The crude discharge rates were (with the exception

Table 2. Lymphatic and hematopoietic diseases, relative risks (RR) with regard to residence in a zip code containing a benzene waste site compared to one without a benzene waste site, ages 20 and above except as noted

\begin{tabular}{llcc}
\hline \multicolumn{1}{c}{ Disease } & \multicolumn{1}{c}{ Crude rate } & Rate for main effects model & Prvalue for main effects rate \\
\hline ALL $^{\mathrm{a}}$ & $1.28(1.15-1.43)^{*}$ & $0.95(0.62-1.46)$ & 0.807 \\
$\mathrm{CLL}$ & $1.25(1.18-1.32)^{*}$ & $1.15(1-1.33)^{*}$ & 0.048 \\
$\mathrm{AML}$ & $1.01(0.92-1.1)$ & $0.94(0.77-1.15)$ & 0.539 \\
$\mathrm{CML}$ & $1.24(1.09-1.4)^{*}$ & $1.09(0.83-1.43)$ & 0.551 \\
$\mathrm{HD}$ & $1.29(1.13-1.47)^{\mathrm{b}}$ & $1.07(0.93-1.24)$ & 0.356 \\
$\mathrm{NHL}$ & $1.09(1.05-1.13)^{*}$ & $1.26(0.96-1.66)$ & 0.089 \\
MM & $1.05(0.99-1.12)$ & $1.01(0.82-1.24)$ & 0.911 \\
Leukemia & $1.15(1.1-1.2)^{*}$ & $1.22(1.04-1.43)^{*}$ & 0.014 \\
Lymphoma & $1.10(1.06-1.14)^{*}$ & $1.17(1.02-1.35)^{*}$ & 0.024 \\
\hline
\end{tabular}

ALL - acute lymphatic leukemia, CLL - chronic lymphatic leukemia, AML — acute myeloid leukemia, CML — chronic myeloid leukemia, HD - Hodgkin's Disease, NHL — non-Hodgkin's lymphoma, MM — multiple myeloma.

${ }^{a}$ Age 1-19; ${ }^{b}$ Ages 40 and above. * Statistically significant at $\mathrm{p}<0.05$. 


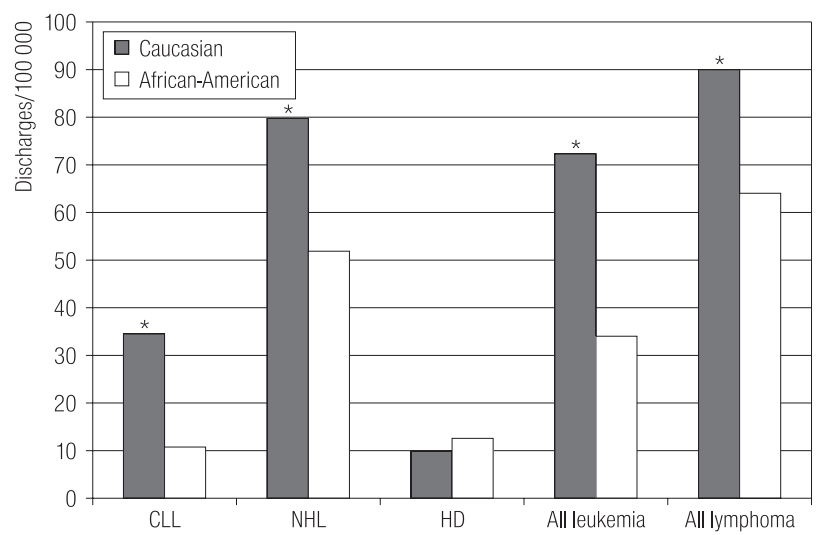

* Significant compared to African-Americans $(\mathrm{P}<0.05)$. CLL — chronic lymphatic leukemia, NHL — non-Hodgkin's lymphoma, HD - Hodgkin's Disease.

Fig. 1. Crude hospital discharge rates for Caucasians and African Americans (discharges per 100000 person years) for some leukemias and lymphomas.

of CLL) either not significantly different between the income groups (HD, all adult leukemia) or significantly different and higher in the higher income groups (NHL, all lymphomas) (Figure 2).

When examining the interactions, we found that race was a significant effect modifier for CLL, HD, NHL and

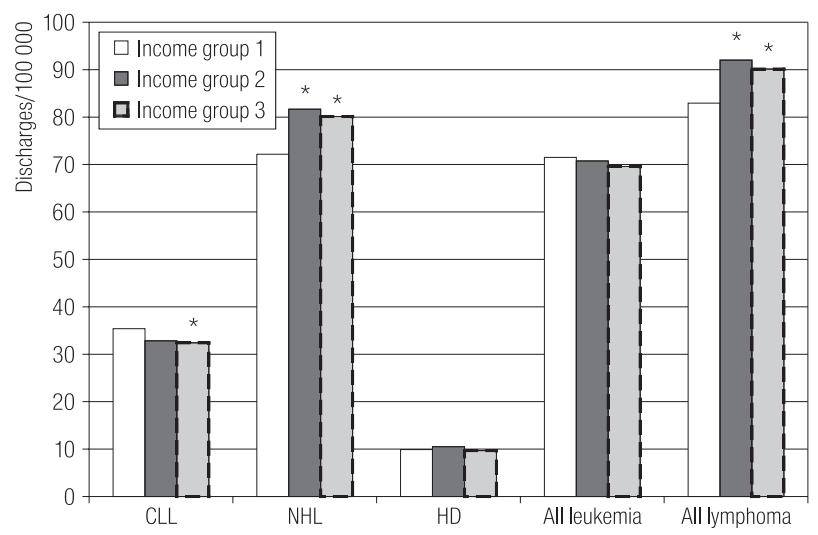

* Significant compared to income group $1(\mathrm{P}<0.05)$. Group 1 is the lowest income group.

Abbreviations as in Figure 1.

Fig. 2. Crude hospital discharge rates for different income groups (discharges per 100000 person years) for some leukemias and lymphomas.

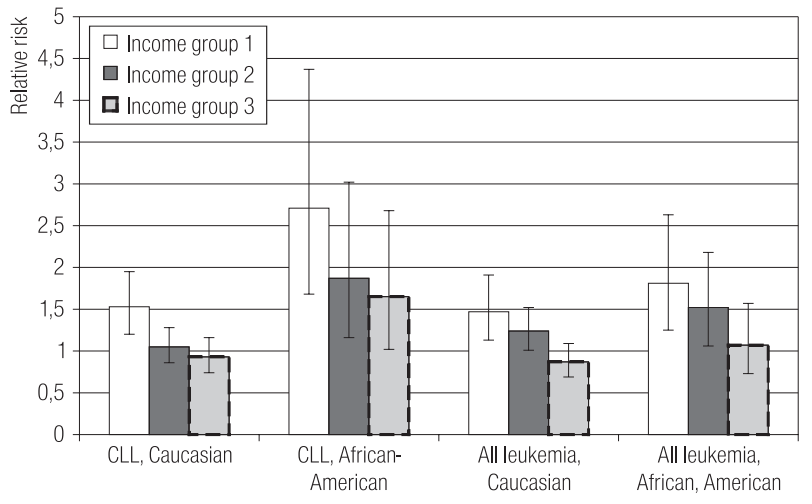

Relative risk of hospitalization for different types of leukemia in relation to benzene exposure and $95 \%$ confidence intervals (displayed as error bars) in the subgroups defined by the interactions between income and exposure, and race and exposure.

P-values for the interactions: CLL, African American vs. Caucasian: 0.015; CLL, income group 2 vs. 1: 0.016; CLL, income group 3 vs. 1: 0.0015; All leukemia, African American vs. Caucasian: 0.24; All leukemia, income group 2 vs. 1: 0.28, All leukemia, income group 3 vs. 1: 0.0015 .

Abbreviations as in Figure 1.

Fig. 3. Results of application of the negative binomial regression model for leukemia.

lymphoma, resulting in a stronger positive relationship between benzene exposure and the disease outcomes in African Americans than in Caucasians. We further found that income was a significant effect modifier for CLL, leukemia, NHL and lymphoma, resulting in a stronger positive relationship between the exposure and the disease outcomes in the lower as compared to higher income groups (Figures 3 and 4).

Gender was a significant effect modifier for AML. We found a $26 \%$ increase in the rate of discharges for AML in the benzene-exposed as compared to unexposed females (RR: 1.26, 95\% CI: 1.01-1.58). In the exposed males there was a $23 \%$ decrease in the rate of discharges compared to the unexposed males (RR: 0.77, 95\% CI: 0.61-0.98). Both gender and race were effect modifiers for the relationship between exposure and discharges for MM. We found a $80 \%$ elevation in the rate of discharges for MM in exposed as compared to unexposed 


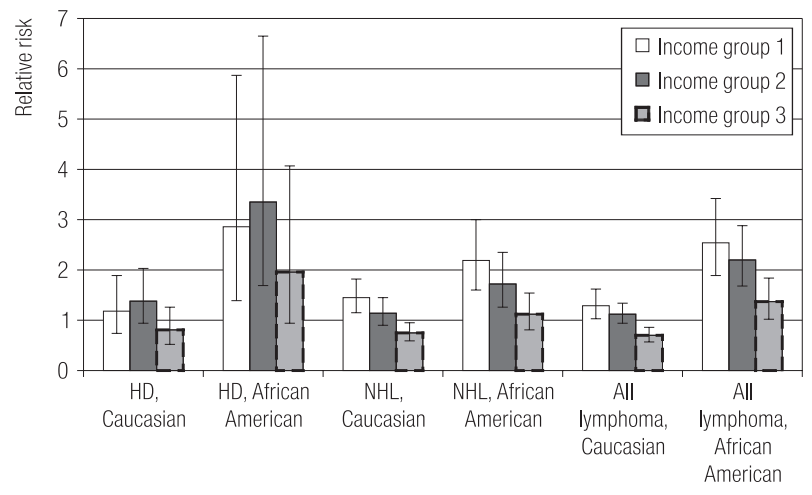

Relative risk of hospitalization for different types of lymphoma in relation to benzene exposure and 95\% confidence intervals (displayed as error bars) in the subgroups defined by the interactions between income and exposure, and race and exposure.

P-values for the interactions: HD, African American vs. Caucasian: 0.0088; HD, income group 2 vs. 1: 0.59; HD, income group 3 vs. 1: 0.21; NHL, African American vs. Caucasian: < 0.0001; NHL, income group 2 vs. 1: 0.065, NHL, income group 3 vs. 1: < 0.0001; All lymphoma, African American vs. Caucasian: 0.0011; All lymphoma, income group 2 vs. 1: 0.84; All lymphoma, income group 3 vs. 1: 0.027. Abbreviations as in Figure 1.

Fig. 4. Results of application of the negative binomial regression model for lymphoma.

African American females that was statistically significant (RR: 1.80, 95\% CI: 1.18-2.74). Exposed Caucasian males had $28 \%$ fewer discharges for MM than unexposed Caucasian males (RR: 0.72, 95\% CI: 0.54-0.97). There were no statistically significant differences between the exposed and unexposed populations in the rates of discharges of MM for African American males and Caucasian females. We did not detect any statistically significant differences in discharges for ALL and CML between benzeneexposed and unexposed populations.

\section{DISCUSSION}

Our study focused on the association between environmental exposure to benzene in the general population, and the rate of hospital discharges for persons with hematopoietic cancers. This relationship has previously not been extensively studied [31]. While there are a number of studies of the effects of benzene in the work place, this study is unique in that it is an ecological study of the general population. Environmentally exposed populations receive benzene concentrations several orders of magnitude lower than the occupationally exposed populations [31], but the exposure is more chronic and effective over a longer period of time. Additionally, the environmental exposure affects the entire population, instead of a healthy working population that usually is predominantly male. Furthermore, using hospital discharges instead of individual level data magnifies the presence of disease in the population, thus allowing comparisons to be made for a rare disease outcome.

Previous population studies of benzene exposure have yielded inconclusive results, perhaps as a consequence of lower concentrations or smaller population size. An Italian ecologic study looked at rates of leukemia and lymphoma in a residential district near a coke plant compared to another district lacking a coke plant and to the entire surrounding area [32]. It found statistically significant elevations of leukemia, all lymphatic and hematopoietic diseases and NHL in male residents of the district with the coke plant compared to the other areas, but failed to show such associations in females. A study on residents near 11 oil refineries in Great Britain did not show any elevation in lymphatic or hematopoietic cancers [33]. One ecologic study in Sweden found a significant relationship between car density and childhood leukemia [25]. A population based case control study in northern Italy similarly found a significant relationship between traffic density (vehicles/ day) and childhood leukemia [34]. However, another study that looked at a population from a previous case control study in Los Angeles was not able to find any association between traffic density and childhood leukemia [35].

The Superfund waste sites in the US have been extensively studied, and are considered "a major environmental and public health concern in the United States and elsewhere" [36]. In 1997 the US EPA reported complete 
exposure pathways (consisting of a source of contamination, an environmental medium, a point of exposure, route(s) of exposure, and a receptor population) in 530 of the 1450 NPL sites [36]. Of the 530 sites with complete exposure pathways, $21 \%$ contained benzene. At $91 \%$ of the sites with completed exposure pathways, the exposure occurred through contaminated ground water. Associations with several forms of cancer and residence near a hazardous waste site have been shown in previous studies [37,38]. A case study of a residence using gasoline-contaminated ground water in 1994 [39] measured concentrations of benzene in the air in different parts of the home after one individual had taken a 20 minute shower in the bathroom. The results suggested a pulse of benzene moving from the shower stall to the rest of the house over a period of 60 minutes after the shower. The estimated benzene exposure resulting from the shower was 2 to 3.5 times higher than the dose received during a concurrent 6 hour occupation in the house. Forty percent of the exposure resulted from inhalation and $60 \%$ from the dermal pathway.

When adjusted for a number of potential confounders we found statistically significantly elevated levels of discharges for all adult lymphoma combined, all adult leukemia combined and CLL in the benzene exposed zip codes compared to those without exposure. The relationships between the exposure and outcome for several hematologic cancers were stronger in population groups that normally have a lower incidence of these diseases (African Americans and persons of lower income). These findings suggest that the exposure to benzene promotes several forms of hematologic cancers and that some population groups are more susceptible, genetically or environmentally, to the exposure than others. The greater effects of benzene exposure seen in the less affluent and African American populations may be due to a higher tendency among these populations to live in the vicinity of the hazardous waste sites within the zip codes defined as exposed. That in turn, might be due to either a selective migration to these areas or due to placement of new waste sites in areas where they live [40-41]. The difference in susceptibility between Caucasians and African Americans may also have a genetic origin. There are reported ethnic differences in the occurrence of activity-reducing polymorphisms in CYP2E1 [42], which could cause differences in susceptibility to benzene exposure between Caucasians and African Americans. Whether or not these differences contribute to the ethnic differences in the disease outcomes seen in our study remains unclear. We are unable to find an explanation for the gender differences in the exposure to outcome relationship that we found for AML and MM. It is also important to note that no association was found between waste sites and ALL, a disease primarily of children.

There are several limitations in our study that makes it impossible for us to prove cause and effect, as is the case for any ecologic study. We have measured benzene exposure and response only at an aggregated level, rather than for individuals, which could possibly introduce aggregation bias. We have adjusted for several potential risk factors for the outcome, but our adjustments for SES and traffic density are crude and at a zip code level only. We have not adjusted for cigarette smoking, which is an important source of benzene exposure, nor for exposure to ionizing radiation a risk factor for several of the diseases studied. These risk factors may confound the results in the unlikely event that their frequencies are associated with the exposure. We have no information on duration of residence in the current ZIP code, which could lead to a migration bias that can affect the validity of ecologic studies, particularly for long-latency, chronic diseases [43]. We have no control for past occupational or residential exposures that are not correlated with an existing and identified hazardous waste site.

One might argue that if, despite the methodological limitations and the crude exposure assessment, we find elevated levels of some hematologic cancers, the real relationship is likely to be much stronger. The results we have obtained in this study are those which we hypothesized based on past occupational studies. Perhaps the strongest 
evidence that use of the SPARCS data, in spite of the limitations, provides valuable information about exposure and disease comes from our previous studies with diabetes and hypertension. The ecologic studies of rates of hospitalization for diabetes [4] and hypertension [24] were followed by studies where serum contaminant levels were directly measured along with medical documentation of these diseases [45-46], thus confirming the hypotheses generated by use of the SPARCS data.

Our observations suggest that an environmental exposure to benzene leads to an increased risk of developing several forms of adult hematologic cancers that necessitate hospitalization, and that the exposure has a higher health impact in the less affluent and African American populations. These differences may be attributable to the tendency of these populations to live closer to the benzene sites, but there may also be genetic and cultural differences. The most likely routes of exposure are through inhalation of benzene that comes either directly from airborne emissions to the atmosphere around the waste sites, or from contaminated ground water that emits benzene upon usage in homes near the waste sites. Although our observations must be viewed as being hypothesis generating, they provide additional support for a relationship between environmental exposure to benzene and risk of hematologic cancers. The strength of this study lies in the large study population (29 million person years) which enables us to detect differences in the occurrences of the rare diseases studied. Further study is necessary to determine whether the relationships suggested here are causative.

\section{ACKNOWLEDGEMENTS}

Supported by the Institute for Health and the Environment, University at Albany, Rensselaer, New York, USA and a traveling grant for students from Linköping University Medical School. The authors declare that they have no conflict of interest.

\section{REFERENCES}

1. Centers for Disease Control and Prevention. Hematologic (Blood) Cancers [cited 2009 May 15]. Available from URL: http://www.cdc.gov/cancer/hematologic.

2. Richardson DB, Wing S, Schroeder J, Schmitz-Feuerhake I, Hoffmann W. Ionizing radiation and chronic lymphocytic leukemia. Environ Health Perspect 2005;113:1-5.

3. Schubauer-Berigan MK, Wenzl TB. Leukemia mortality among radiation-exposed workers. Occup Med 2001;16: 27187.

4. National Cancer Institute. Surveillance Epidemiology and End Results [cited 2009 May 13]. Available from URL: http:// seer.cancer.gov/faststats.

5. Müller AM, Ihorst G, Mertelsmann R, Engelhardt M. Epidemiology of non-Hodgkin's lymphoma (NHL): trends, geographic distribution, and etiology. Ann Hematol 2005;84:1-12.

6. Grufferman S, Delzell E. Epidemiology of Hodgkin's disease. Epidemiol Rev 1984;6:76-106.

7. International Agency for Research on Cancer. Some industrial chemicals and dyestuffs. IARC Monogr Eval Carcinog Risk Hum 1982;29:93-4.

8. Hayes RB, Yin SN, Dosemeci M, Li GL, Wacholder S, Travis $\mathrm{LB}$, et al. Benzene and the dose-related incidence of hematologic neoplasms in China. J Natl Cancer Inst 1997;89: 1065-71.

9. Rinsky RA. Benzene and leukemia. An epidemiologic risk assessment. Environ Health Perspect 1989;82:189-91.

10. Collins JJ, Ireland B, Buckley CF, Shepperly D. Lymphohaematopoeitic cancer mortality among workers with benzene exposure. Occup Environ Med 2003;60:676-9.

11. Ireland B, Collins JJ, Buckley CF, Riordan SG. Cancer mortality among workers with benzene exposure. Epidemiology 1997;8:318-20.

12. Agency for Toxic Substances and Disease Registry. Toxicological profile for benzene. Atlanta, GA: US Department for Health and Human Services, Public Health Service; 2007 [cited 2009 May 28]. Available from URL: http:// www.atsdr.cdc.gov/toxprofiles/tp3.html. 
13. US Environmental Protection Agency. Toxic Release Inventory, TRI explorer [cited 2009 April 29]. Available from: $\mathrm{http}: / /$ www.epa.gov/triexplorer.

14. Mackay D, Leinonen PJ. Rate of evaporation of low-solubility contaminants from water bodies to atmosphere. Environ Sci Technol 1975;9:1178-80.

15. Wallace L. Environmental exposure to benzene: an update. Environ Health Perspect 1996;104:1129-36.

16. Wallace L. Major sources of benzene exposure. Environ Health Perspect 1989;82:165-9.

17. Ashley DL, Bonin MA, Cardinali FL, McCraw JM, Wooten JV. Blood concentrations of volatile organic compounds in a non occupationally exposed US population and in groups with suspected exposure. Clin Chem 1994;40: $1401-4$.

18. Rothman N, Smith MT, Hayes RB, Traver RD, Hoener $\mathrm{B}$, Campleman S, et al. Benzene poisoning, a risk factor for hematological malignancy, is associated with the NQO1 609 $C \rightarrow T$ mutation and rapid fractional excretion of chlorzoxazone. Cancer Res 1997;57:2839-42.

19. Nebert DW, Roe AL, Vandale SE, Bingham E, Oakley GG. $N A D(P) H: Q u i n o n e$ oxidoreductase (NQO1) polymorphism, exposure to benzene, and predisposition to disease: $A H u G E$ review. Genet Med 2002;4:62-70.

20. Wan J, Shi J, Hui L, Wu D, Jin X, Zha N. Association of genetic polymorphisms in CYP2E1, MPO, NQO1, GSTM1, and GSTT1 genes with benzene poisoning. Environ Health Perspect 2002;110:1213-8.

21. National Center for Health Statistics. International Classification of Diseases, 9th Revision, Clinical Modification: ICD-9-CM. 2nd ed. PHS 80-1260. Washington (DC): U.S. Government Printing Office; 1980.

22. Glaser SL, Jarret RF. The epidemiology of Hodgkin's disease. Baillieres Clin Haematol 1996;9:401-16.

23. Shcherbatykh I, Huang X, Lessner L, Carpenter DO. Hazardous waste sites and stroke in New York State. Environ Health 2005;4:18.
24. Huang X, Lessner L, Carpenter DO. Exposure to persistent organic pollutants and hypertensive disease. Environ Res 2006;102:101-6.

25. Nordlinder R, Järvholm B. Environmental exposure to gasoline and leukemia in children and young adults - an ecology study. Int Arch Occup Environ Health 1997;70:57-60.

26. US Census Bureau. Census 2000 Urban and Rural Classification [cited 2009 May 13]. Available from URL: http://www. census.gov/geo/www/ua/ua_2k.html.

27. US Environmental Protection Agency. National Priorities List [cited 2009 May 11]. Available from URL: http://www. epa.gov/superfund/sites/npl/index.htm.

28. US Environmental Protection Agency. Great Lakes Area of Concerns [cited 2009 May 29]. Available from: http://epa. gov/glnpo/aoc/index.html.

29. Woodward M. Epidemiology: study design and data analysis. Chapman \& Hall/CRC Press; 1999.

30. Cameron C, Trivedi PK. Regression Analysis of Count Data, Econometric Society Monograph No. 30. Cambridge, UK: Cambridge University Press; 1998.

31. Duarte-Davidson R, Courage C, Rushton L, Levy L. Benzene in the environment: an assessment of the potential risks to the health of the population. Occup Environ Med 2001;58:2-13.

32. Parodi S, Vercelli M, Stella A, Stagnaro E, Valerio F. Lymphohaematopoietic system cancer incidence in an urban area near a coke oven plant: an ecological investigation. Occup Environ Med 2003;60:187-94.

33. Wilkinson P, Thakrar B, Walls P, Landon M, Falconer S, Grundy C, et al. Lymphohaematopoietic malignancy around all industrial complexes that include major oil refineries in Great Britain. Occup Environ Med 1999;56:577-80.

34. Crosignani P, Tittarelli A, Borgini A, Codazzi T, Rovelli A, Porro E. Childhood leukemia and road traffic: A populationbased case-control study. Int J Cancer 2004;108:596-9.

35. Langholtz B, Ebi K, Thomas DC, Peters JM, London SJ. Traffic density and the risk of childhood leukemia in a Los Angeles case-control study. Ann Epidemiol 2002;12:482-7. 
36. Johnson BL, DeRosa CT. The toxicologic hazard of Superfund hazardous waste sites. Rev Environ Health 1997;12: 235-51.

37. Griffith J, Duncan RC, Riggan WB, Pellom AC. Cancer mortality in U.S. counties with hazardous waste sites and ground water pollution. Arch Environ Health 1989;44:69-74.

38. Najem GR, Thind IS, Lavenhar MA, Louria DB. Gastrointestinal cancer mortality in New Jersey counties, and the relationship with environmental variables. Int $\mathrm{J}$ Epidemiol 1983;12:276-89.

39. Lindstrom AB, Highsmith VR, Buckley TJ, Pate WJ, Michael LC. Gasoline-contaminated ground water as a source of residential benzene exposure: A case study. J Expos Anal Environ Epidemiol 1994;4:183-95.

40. Soliman MR, Derosa CT, Mielke HW, Bota K. Hazardous wastes, hazardous materials and environmental health inequity. Toxicol Ind Health 1993;9:901-12.

41. Woodward A, Boffetta P. Environmental exposure, social class, and cancer risk. In: Kogevinas M, Pearce M, Susser N, Boffetta P, editors. Social Inequalities and Cancer. Lyon, France: IARC Sci Publ; 1997. p. 361-7.
42. Stephens EA, Taylor JA, Kaplan N, Yang CH, Hsieh LL, Lucier GW, et al. Ethnic variation in the CYP2E1 gene: polymorphism analysis of 695 African-Americans, European-Americans and Taiwanese. Pharmacogenetics 1994;4: 185-92.

43. Tong S. Migration bias in ecologic studies. Eur J Epidemiol 2000;16:365-9.

44. Kouznetsova M, Huang X, Ma J, Lessner L, Carpenter DO. Increased rate of hospitalization for diabetes and residential proximity of hazardous waste sites. Environ Health Perspect 2007;115:75-9.

45. Codru N, Schymura MJ, Negoita S, The Akwesasne Task Force on the Environment, Rej R, Carpenter DO. Diabetes in relation to serum levels of polychlorinated biphenyls (PCBs) and chlorinated pesticides in adult Native Americans. Environ Health Perspect 2007;115:1443-7.

46. Goncharov A, Bloom M, Pavuk M, Birman I, Carpenter DO. Blood pressure and hypertension in relation to levels of serum polychlorinated biphenyls in residents of Anniston, Alabama. J Hyperten 2010;28:2053-60.

This work is available in Open Access model and licensed under a Creative Commons Attribution-NonCommercial 3.0 Poland License - http://creativecommons.org/ licenses/by-nc/3.0/pl/deed.en. 